\title{
WHY CHINA STINKS. DEFICIENCIES IN PLUMBING AND VENTILATION SYSTEMS IN CHINA
}

\author{
Alex A. Volinsky, Ph.D. \\ Department of Mechanical Engineering, University of South Florida \\ 4202 E. Fowler Ave. ENG030, Tampa, Florida 33620 \\ Email: volinsky@usf.edu
}

\begin{abstract}
Viruses can potentially spread through sewage and ventilation systems. This paper addresses the sources of offensive smell in China due to exposed sewage lines in commercial and residential buildings. Several examples are provided along with the specific instructions on how to solve these problems short-term for travelers and longterm residents. Ultimately this global problem can be solved by government intervention and setting up government offices enforcing building codes with appropriate inspection structures.
\end{abstract}

Keywords: China; plumbing; ventilation; sewage; health safety; public health

Cite this Article: Alex A. Volinsky, Why China Stinks. Deficiencies in Plumbing and Ventilation Systems in China, International Journal of Civil Engineering and Technology, 11(7), 2020, pp. 16-20.

https://iaeme.com/Home/issue/IJCIET?Volume=11\&Issue=7

\section{INTRODUCTION}

Viruses and other pathogens can potentially spread through ventilation systems [[1]], possibly rendering regular quarantine activities associated with the latest COVID-19 virus outbreaks useless. Sewer gas is toxic and can cause explosions [[2]-[5]]. Developed countries have building codes and laws, along with the enforcement agencies and organizations, which make sure that the sewage lines are properly sealed and do not adversely affect the health of the population [[6]-[8]]. Typically, these laws are enforced by local government agencies.

Offensive sewage odor is noticeable all across China, especially by the foreign noses [[9][11]]. This includes airports, hotels, public buildings, and even universities. The Chinese population is used to this smell and little attention has been paid to this problem for many years since the new modern construction in China presents the same problems.

\section{DISCUSSION}

The author has been periodically visiting China since 2007 and has been puzzled by the problem, thinking that it's only the lack of a trap underneath the sink and toilets that causes 
the bad smell. A trap is a simple device where a sewage pipe is bent in a way that water stays in the pipe, preventing sewer gas from escaping [[12]].

Figure 1 shows a typical Chinese bathroom in Beijing. There's no trap underneath the sink, leaving the sewage line exposed through the drainage pipe. Several other problems are noticeable in Figure 1. The connection between the flexible drain pipe and the sewage line is not sealed. Thus, the bad smell would still be present even if there was a trap. The floor drain is also present, which also doesn't have a water trap.

Figure 2 shows the floor of a typical shower in China, where the drain in the floor doesn't have a water trap, allowing sewer gasses to escape through an exposed sewage pipe. However, proper floor drains with a trap are available and are not that more expensive than the regular floor drains [[13]].

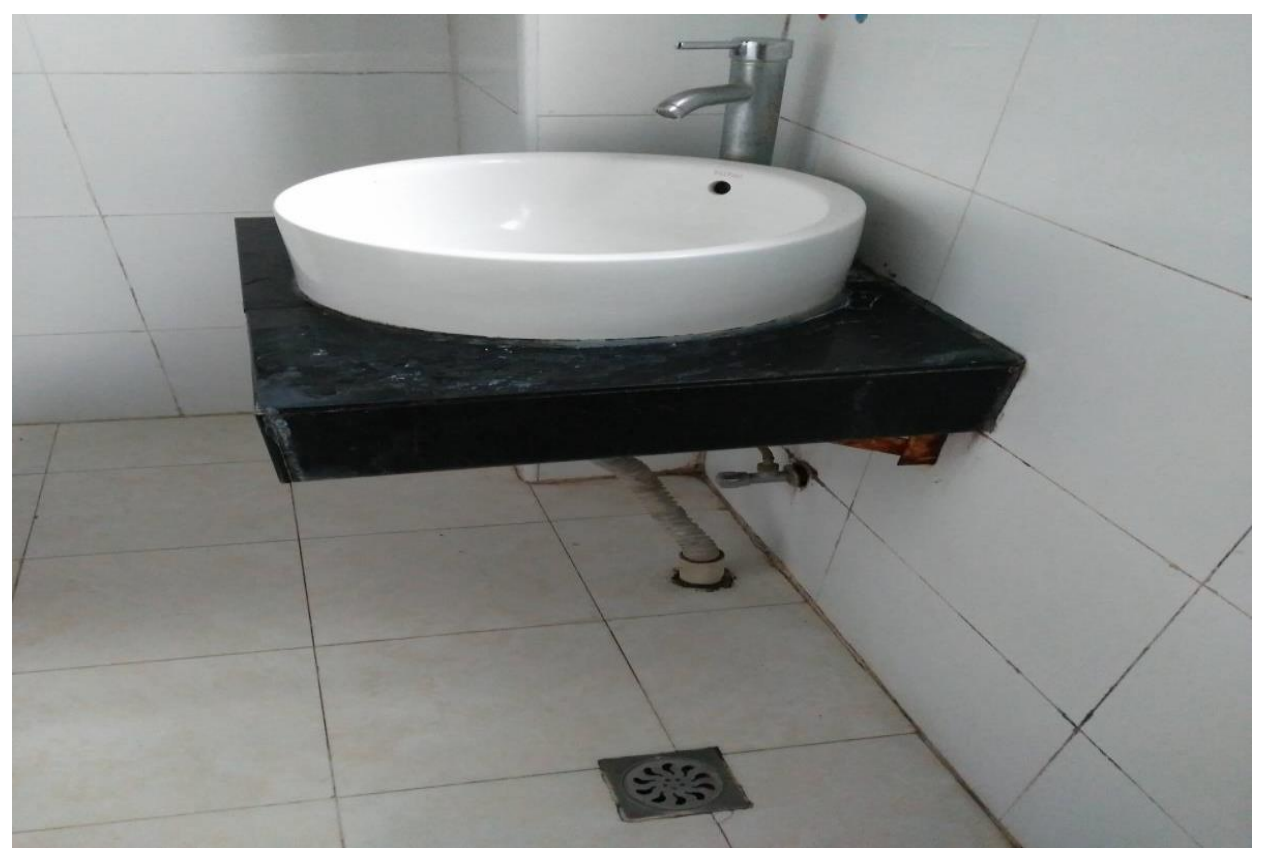

Figure 1 Photo of a typical Chinese bathroom showing a sink without water trap, unsealed sewage line and floor drain without a trap.

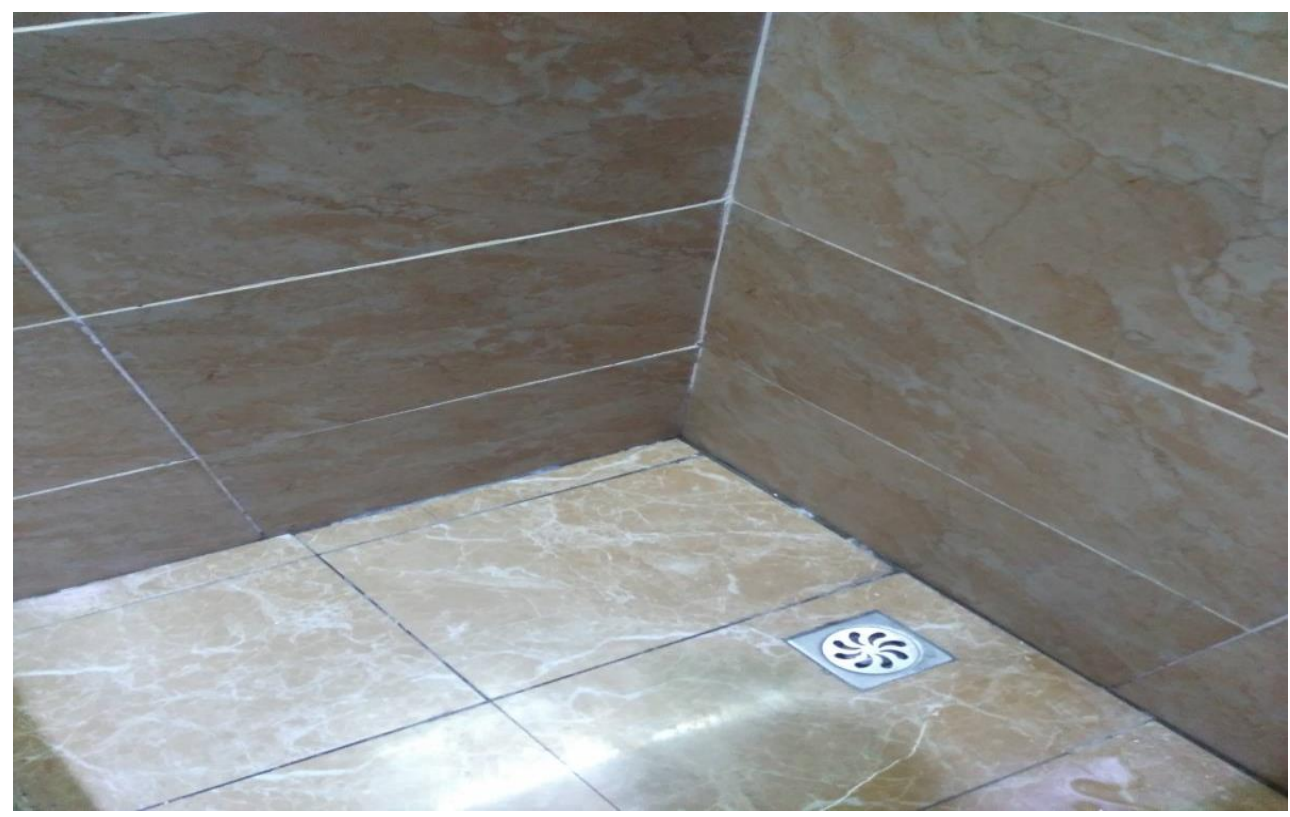

Figure 2 Typical Chinese shower floor with a drain, which doesn't have a trap. 
Similar problems are present in kitchens. Figure 3 shows a kitchen sink without a trap and clearly visible unsealed sewage pipe.

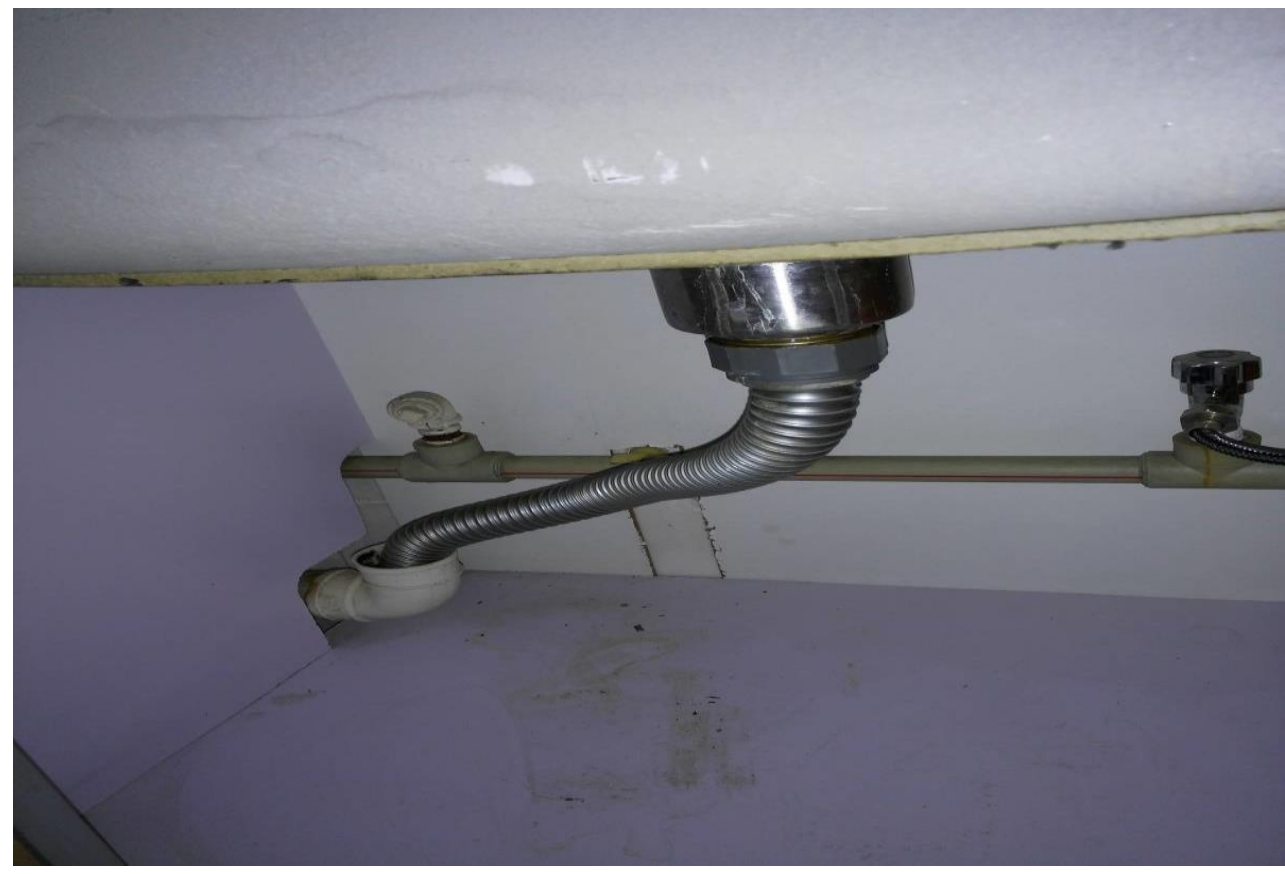

Figure 3 Flexible pipe connection in the kitchen without the water trap showing exposed unsealed drain pipe.

The last problem is associated with ventilation. Even if the sewage lines are properly sealed, and traps are present in all plumbing fixtures, offensive odors from other apartments still enter through the vent shown in Figure 4. These vents are in both bathrooms and kitchens, and are required for proper ventilation. However, in the presence of exposed sewage pipes, they act as additional sources of sewer gas from the neighbors, potentially carrying viruses and pathogens.

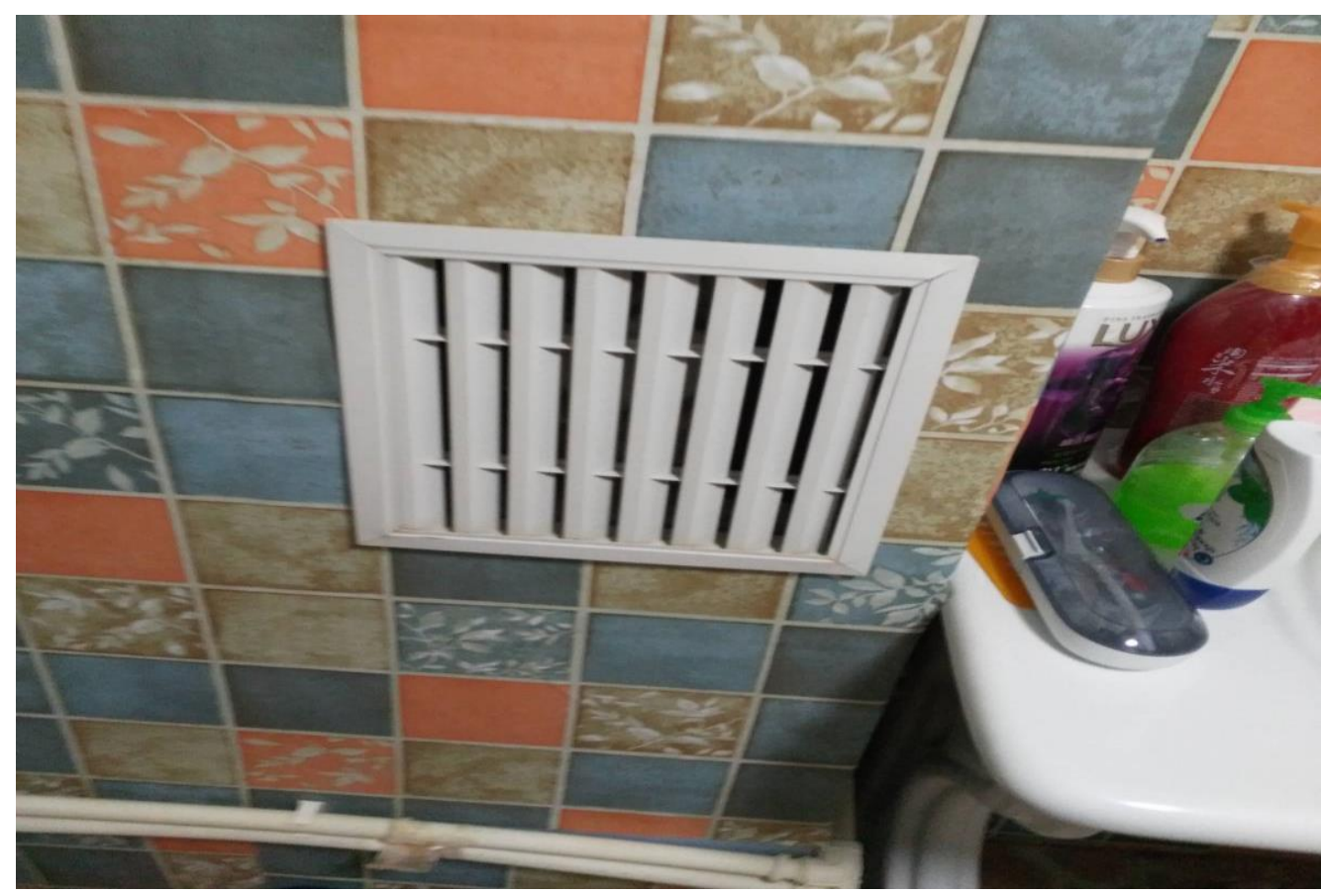

Figure 4 Bathroom vent carrying offensive odors from other apartments. 


\section{SHORT-TERM SOLUTIONS}

If you are traveling in China short-term and notice a foul smell, there are simple ways to eradicate it.

- Flexible pipe underneath the sink can be bent to form a trap. If not, place a plastic bag filled with water into the sink.

- The unsealed connection between the sink and the sewage pipe can be temporarily sealed by wrapping a plastic bag or a piece of clothes over the connection.

- Drain in the shower floor can be temporarily blocked by a plastic bag filled with water.

- Vents in bathrooms and kitchens can be temporarily blocked with a plastic bag or a piece of paper.

These are short-term solutions for travelers, while long-term solutions require more effort and resources.

\section{LONG-TERM SOLUTIONS}

The Chinese people and the Chinese government must realize that the problems described in this paper objectively exist and must be addressed. In your own apartment, you can fix most of these problems by installing traps and sealing sewage lines. There are companies in China that provide these services commercially. However, the vents will have to remain blocked to avoid gas traveling from other apartments. Another solution is to install an electric exhaust fan into the vent.

On the scale of the whole country, the Chinese government must pass and enforce the building laws, starting from hotels and government buildings, universities and such. Code enforcement inspection offices must be set up similar to other developed countries. One of the reasons these problems exist is because typical apartments in China are sold with plumbing rough-ins and no installed fixtures or appliances. In universities, hotels and government buildings the final inspections are made by local representatives not familiar with building norms and codes. It is very important to make sure that the newly constructed buildings are compliant with the construction codes. The author truly believes that the Chinese people and the Chinese government can solve these problems, and the whole country will not stink as it does now.

\section{CONCLUSIONS}

In conclusion, the paper identified common problems with exposed sewage lines in China and provided both short-term solutions for travelers and long-term solutions for the Chinese people.

\section{ACKNOWLEDGEMENTS}

The author acknowledges support from the National Science Foundation, which supported travel and research in China (IRES 1358088).

\section{DATA AVAILABILITY}

All data, models, and code generated or used during the study appear in the submitted article. 


\section{REFERENCES}

[1] S.M. Goyal, S. Anantharaman, M.A. Ramakrishnan, S. Sajja, S. Won Kim, N.J. Stanley, J.E. Farnsworth, T.H. Kuehn, P.C.Raynor, Detection of viruses in used ventilation filters from two large public buildings, American Journal of Infection Control 39(7), e30-e38, 2011

[2] C. Yalamanchili, M.D. Smith, Acute hydrogen sulfide toxicity due to sewer gas exposure, The American Journal of Emergency Medicine 26(4), 518.e5-518.e7, 2008

[3] City of Marion, Ohio, (2020), Everything you always wanted to know about sewer gas...But were afraid to ask. [Online] Available:

http://www.marionohio.us/wpc/sewer_gas (February 14, 2020)

[4] Sewer gas, (2019). [Online] Available: https://en.wikipedia.org/wiki/Sewer_gas (February 14, 2020)

[5] Goss, Stanley (2018), Are home sewage leaks harmful to humans? [Online] Available: https://www.hunker.com/12581801/are-home-sewage-leaks-harmful-to-humans (February 14, 2020)

[6] Chapter 7, Sanitary Drainage, (2017), 2017 Florida Building Code - Plumbing, Sixth Edition. [Online] Available: https://codes.iccsafe.org/public/document/FPC2017/chapter7-sanitary-drainage (February 14, 2020)

[7] Construction norms and practices. Building internal plumbing and canalization. SNIP 2.04.01-85, (1985). [Online] Available: http://www.stelmarket.ru/teh_inf/12_17.htm (in Russian, February 14, 2020)

[8] The Ontario Building Code, Cleanouts for drainage systems, (2018). [Online] Available: http://www.buildingcode.online/1055.html (February 1, 2018)

[9] The Beijinger forum, Stench in bathroom, (2006). [Online] Available: http://www.thebeijinger.com/forum/2006/03/03/stench-bathroom (February 14, 2020)

[10] Why do toilets in China smell so bad? Is there some other reason for the smell such as the cleaning products they use or some chemical only found in Asian excretions? (2017). [Online] Available: https://www.quora.com/Why-do-toilets-in-China-smell-so-bad-Isthere-some-other-reason-for-the-smell-such-as-the-cleaning-products-they-use-or-somechemical-only-found-in-Asian-excretions

[11] MacLeod, Calum, (2013), China counts flies, grades public bathroom stench. [Online] Available: https://www.usatoday.com/story/news/world/2013/02/23/china-publicbathroom/1940727/ (February 23, 2013)

[12] Trap (plumbing), (2020). [Online] Available: https://en.wikipedia.org/wiki/Trap_(plumbing) (February 8, 2020)

[13] Floor drain odor problems, (2015), Free Encyclopedia of Building \& Environmental Inspection, Testing, Diagnosis, Repair. [Online] Available:

https://inspectapedia.com/plumbing/Floor_Drain_Odors_Diagnose.php (January 10, 2015) 